\title{
Compliant vascular models 3D printed with the Stratasys J750: a direct characterization of model distensibility using intravascular ultrasound
}

Adam J. Sparks ${ }^{1}$, Cody M. Smith ${ }^{1}$, Ariana B. Allman ${ }^{1}$, Jillian L. Senko ${ }^{1}$, Karen M. Meess ${ }^{1}$, Richard W. Ducharme ${ }^{1}$, Michael E. Springer ${ }^{1}$, Muhammad Waqas ${ }^{2}$ and Adnan H. Siddiqui ${ }^{1,2,3^{*}}$

\begin{abstract}
Purpose: The purpose of this study is to evaluate biomechanical accuracy of 3D printed anatomical vessels using a material jetting printer (J750, Stratasys, Rehovot, Israel) by measuring distensibility via intravascular ultrasound.

Materials and methods: The test samples are 3D printed tubes to simulate arterial vessels (aorta, carotid artery, and coronary artery). Each vessel type is defined by design geometry of the vessel inner diameter and wall thickness. Vessel inner diameters are aorta $=30 \mathrm{~mm}$, carotid $=7 \mathrm{~mm}$, and coronary $=3 \mathrm{~mm}$. Vessel wall thickness are aorta $=3 \mathrm{~mm}$, carotid $=1.5 \mathrm{~mm}$, and coronary $=1 \mathrm{~mm}$. Each vessel type was printed in 3 different material options. Material options are user-selected from the $\mathbf{J 7 5 0}$ printer software graphical user interface as blood vessel wall anatomy elements in 'compliant', 'slightly compliant', and 'rigid' options. Three replicates of each vessel type were printed in each of the three selected material options, for a total of 27 models. The vessels were connected to a flow loop system where pressure was monitored via a pressure wire and cross-sectional area was measured with intravascular ultrasound (IVUS). Distensibility was calculated by comparing the \% difference in cross-sectional area vs. pulse pressure to clinical literature values. Target clinical ranges for normal and diseased population distensibility are $10.3-44 \%$ for the aorta, $5.1-10.1 \%$ for carotid artery, and 0.5-6\% for coronary artery.

Results: Aorta test vessels had the most clinically representative distensibility when printed in user-selected 'compliant' and 'slightly compliant' material. All aorta test vessels of 'compliant' material $(n=3)$ and 2 of 3 'slightly compliant' vessels evaluated were within target range. Carotid vessels were most clinically represented in distensibility when printed in 'compliant' and 'slightly compliant' material. For carotid test vessels, 2 of 3 'compliant' material samples and 1 of 3 'slightly compliant' material samples were within target range. Coronary arteries were most clinically represented in distensibility when printed in 'slightly compliant' and 'rigid' material. For coronary test vessels, 1 of 3 'slightly compliant' materials and 3 of 3 'rigid' material samples fell within target range.
\end{abstract}

\footnotetext{
* Correspondence: asiddiqui@ubns.com

'The Jacobs Institute, Buffalo, New York, USA

${ }^{2}$ Department of Neurosurgery, University at Buffalo, State University of New

York, 100 High Street, Suite B4, Buffalo, NY 14203, USA

Full list of author information is available at the end of the article
}

\section{$\triangle B M C$}

(c) The Author(s). 2021 Open Access This article is licensed under a Creative Commons Attribution 4.0 International License, which permits use, sharing, adaptation, distribution and reproduction in any medium or format, as long as you give appropriate credit to the original author(s) and the source, provide a link to the Creative Commons licence, and indicate if changes were made. The images or other third party material in this article are included in the article's Creative Commons licence, unless indicated otherwise in a credit line to the material. If material is not included in the article's Creative Commons licence and your intended use is not permitted by statutory regulation or exceeds the permitted use, you will need to obtain permission directly from the copyright holder. To view a copy of this licence, visit http://creativecommons.org/licenses/by/4.0/ The Creative Commons Public Domain Dedication waiver (http://creativecommons.org/publicdomain/zero/1.0/) applies to the data made available in this article, unless otherwise stated in a credit line to the data. 
Conclusions: This study suggests that advancements in materials and 3D printing technology introduced with the J750 Digital Anatomy 3D Printer can enable anatomical models with clinically relevant distensibility.

Keywords: 3D-Printing, Vasculature, Compliance, Intravascular Ultrasound, Distensibility

\section{Background}

Cardiovascular disease is the number one cause of death globally, creating a demand for accelerated and wellinformed endovascular device development [1]. There is an evolving need for accurate vascular models to support this rapid device development. Currently, there are various benchtop models including 2D rigid [2], 3D printed (3DP) rigid [3], 3DP compliant [4], silicone [5], and exvivoplatforms [6]. Although in-vivotesting is an essential phase of device development, benchtop models offer more durable and cost effective solutions, include a quicker turnaround time for manufacture, and have a longer shelf life [7-9].

Specifically, material jetting 3D-printing capabilities are evolving within the realm of medicine to provide clinicians and engineers with life-like patient-specific models for medical device development, physician training, surgical demonstration, and strategic procedural planning. These 3DP models can replicate patient-based vessel geometry within 125-microns [10]. In addition, material jetted 3D printed models can mimic disease states such as calcifications or lesions and be printed in various colors and material stiffnesses [11, 12]. To aid in simulating biomechanical properties of vessel walls, the vasculature may be printed using a variety of compliant materials. Material jetted 3D-printed anatomical models can be designed for use in a flow loop with physiological pressurized conditions for device testing under various imaging modalities such as planar x-ray [13], Computed Tomography [14], Magnetic Resonance [15] and ultrasound [16].

In the material jetting 3D printing community, there have been continuous efforts to replicate physiological characteristics in the 3D printed in-vitro models such as material selection, vessel geometry, lubricity, and elastic properties. Tabaczynski et al. characterized material properties of vascular models that best mimic healthy and diseased vessels. In addition, Tabaczynski's other work has included characterizing vessel lubricity along a multi-material vessel path comprised of rigid reinforcements and compliant vessel wall which results in smooth and accurate device trackability within the vessel lumen $[9,11]$. Furthermore, testing of different vessel wall thicknesses to vary vessel distensibility under a pressurized flow loop allows a more accurately represented invitrobenchtop system $[9,11]$. Studies conducted using a J750 3D Printer, prior to the release of the J750 Digital Anatomy 3D Printer, indicated that preset materials may not be sufficient to replicate the arterial wall with physiological accuracy $[9,11]$. The J750 printer can employ multiple materials within a single printed model, which provides many options to vary mechanical properties. Stratasys' J750 Digital Anatomy 3D Printer materials established six new preset blood vessel wall compliance options, thereby improving the ability to create vascular models with various biomechanical properties.

Arterial distensibility is defined as an artery's capacity to expand in response to an increase in blood pressure [17]. Cross-sectional distensibility is calculated by the relative change in lumen area for a given pressure change $(\Delta \mathrm{A} / \mathrm{A} \times \Delta \mathrm{P}$, where $\Delta \mathrm{A}$ is change in lumen cross-sectional area between systole and diastole, $\mathrm{A}$ is lumen cross-sectional area in diastole, and $\Delta \mathrm{P}$ is local pulse pressure), expressed in units of $\% \Delta \mathrm{A} / 100 \mathrm{mmHg}$. Clinical values for distensibility are $10.3-44 \%$ for aorta arterial vessels, $5.1-10.1 \%$ for carotid arterial vessels, and $0.5-6 \%$ for coronary arterial vessels [17-19]. To enhance the simulation of evaluating device performance by a clinician, vascular models that feature distensibility can be a useful biomechanical attribute. To mimic native distensibility, 3D-printed vascular models' materials must functionally replicate vessel change in crosssectional area under physiological blood pressures [20]. With the option of using J750 materials, there is a possibility to simulate clinically relevant distensibility in 3DP arterial vessels. The opportunity to select vessel compliance material on the printer's software graphic user interface (GUI) could allow for simulation of a wide range of vessel distensibility and therefore a more accurate assessment of vascular devices.

Clinically, physicians routinely use intravascular ultrasound (IVUS) to characterize vasculature such as inner lumen geometry and cross-sectional area [18, 21]. The IVUS system outputs a cross sectional image which can be measured, and along with measuring pulse pressure, distensibility can be calculated. IVUS catheters detect inner lumen diameter by propagating sound waves to the blood vessel and computing the signal reflected from the walls. Although designed for use in native vasculature, 3D-printed material in a water flow loop provides a compatible in-vitro environment for performing measurements for this study. Using the same clinical IVUS equipment to measure 3D-printed vessels reduces error of converting data from other measurement systems, providing a direct comparison to clinically reported values. 
In this study, we aim to evaluate the distensibility of various 3D printed vessels using a J750 printer and compare with distensibility values of in-vivo vessels reported in literature.

\section{Methods}

\section{D printed vessel samples}

Three different modeled artery types including aorta, carotid, and coronary were evaluated for cross-sectional distensibility using different material blends to understand changes across varying inner lumen diameters. Table 1identifies the vessel configuration study parameters produced on a material jetting printer (J750, Stratasys, Rehovot, Israel) [11]. The representative inner lumen diameter for each vessel type was selected from literature [22-25]. The vessel model was designed in Solidworks (Waltham, MA, USA) using a series of geometric sketches and extrusions. Wall thickness was selected based on previous experience for withstanding physiological pressure and demonstrating desired vessel behavior (Table 1) [11, 22, 23, 26, 27]. Vessels were designed as straight tubes to promote consistent cross-sectional measures when using the IVUS system. Vessels feature rigid adaptors on each end to interface with a flow loop fixture. The model was then converted to a stereolithography (STL) file and imported into Stratasys printing software (GrabCAD Print, version 1.36) for building print trays and material selection.

GrabCAD Print offers six material combinations for blood vessel wall materials. The vessel wall materials are comprised of a mixture of a flexible material (Agilus30, shore hardness $30 \mathrm{~A}$ ) and a rigid material (Vero, shore hardness 83D). The material mixture options in the software GUI provides 6 compliance options from 'Compliant' to 'Rigid' (Fig. 1) on a sliding dial. As the user slides from one compliance to another, the software algorithm changes the bulk material properties by affecting the ratio of Agilus30 to Vero.

The compliance option chosen for each vessel type for this study was 'Compliant', 'Slightly Compliant', and 'Rigid'. Vessels were printed with GelSupport as internal support material with matte finish and heavy grid style as the outside support. Once successfully printed (Fig. 2B), support material was removed using standard model processing techniques. Water was used to rinse bulk support material from the models. An agitated bath of sodium hydroxide $\left(2 \% \mathrm{NaOH}\right.$ and $\left.1 \% \mathrm{Na}_{2} \mathrm{SiO}_{3}\right)$ was used to chemically clean models for $20 \mathrm{~min}$. Once chemically cleaned, the models were rinsed with water and allowed to dry. Inlet and outlet connectors were attached to the rigid adaptors with adhesive (Fig. 2C). Post processing work per sample took approximately $30 \mathrm{~min}$ of hands-on labor.

\section{Flow system setup}

Each sample was installed onto a holding fixture which allowed the vessel ends to move freely in the axial direction. One side was anchored, while the other was attached to a linear bearing to allow motion along the length of the vessel (Fig. 3). Allowing the vessels to stretch along the length is important, as restricting the axial expansion could artificially increase the change in lumen area. The flow loop setup (Fig. 4) was consistent for all vascular models and testing was performed using a pulsatile pump (55-3305, Harvard Apparatus, MA, USA). The pulsatile pump provides cyclical pulsatile flow with an adjustable cardiac output and is connected to the flow model's inlet via silicone tubing. Silicone tubing is connected to the outlet and to the heated reservoir system. A flow restrictor was used on the outflow tubing to help achieve target pressures. Water was circulated through the flow loop system and water bath temperature was maintained at $37.5 \pm$ $0.5{ }^{\circ} \mathrm{C}$. The target temperature of $37.5{ }^{\circ} \mathrm{C}$ was selected to mimic human body temperature, and temperature conditions were controlled as material properties can change with temperature. Target pressure of $120 / 80 \mathrm{mmHg}$ was selected to mimic physiological values, with a mean arterial pressure (MAP) of $100 \pm 5 \mathrm{mmHg}$ and pulse pressure of $40 \pm 5 \mathrm{mmHg}[24,25,28]$. MAP and pulse pressure were monitored via a Volcano pressure wire system (Andover, MA, USA) and regulated per vessel type by adjusting the pump volume/stroke setting. Pulsatile pump diastolic/

Table 1 Summary of study parameters $[11,22,23,26,27]$

\begin{tabular}{|c|c|c|c|c|c|}
\hline Artery Type & Inner Diameter, ID [mm] & Wall Thickness, WT [mm] & Vessel Length, [mm] & Compliance Material Options & Samples \\
\hline \multirow[t]{3}{*}{ Aorta } & 30.0 & 3.0 & 150 & Compliant & 3 \\
\hline & & & & Slightly Compliant & 3 \\
\hline & & & & Rigid & 3 \\
\hline \multirow[t]{3}{*}{ Carotid } & 7.0 & 1.5 & 150 & Compliant & 3 \\
\hline & & & & Slightly Compliant & 3 \\
\hline & & & & Rigid & 3 \\
\hline \multirow[t]{3}{*}{ Coronary } & 3.0 & 1.0 & 115 & Compliant & 3 \\
\hline & & & & Slightly Compliant & 3 \\
\hline & & & & Rigid & 3 \\
\hline
\end{tabular}




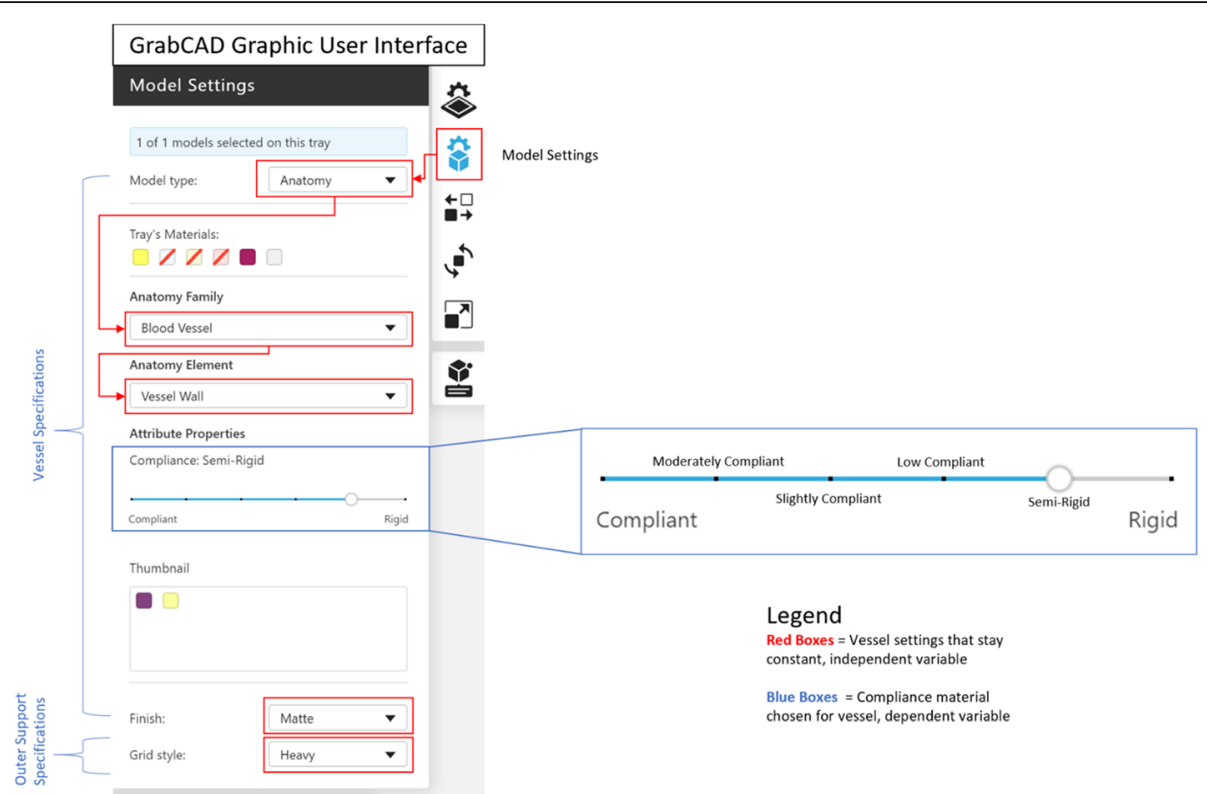

Fig. 1 J750 Graphic User Interface (GUI), GrabCAD Print - Model Settings. On the GUI, the user can choose model type, view the materials that are in the printer at time of use, and select the desired anatomy type (anatomy family/element). These settings were the independent variable of the study in terms of vessel material selection and can be seen in the corresponding red boxes. The 'attribute properties' are the dependent variable in terms of vessel material selection and can be chosen along the sliding dial as seen in the corresponding blue boxes

systolic phase ratio and rate remained constant at 35/65 \% phase ratio, and 60 revolutions per minute, respectively $[29,30]$. Air bubbles were eliminated via an in-line compliance chamber included in the inlet tubing. Volume of water in the compliance chamber was adjusted in conjunction with pump volume/stroke output until target pressure conditions were met.

\section{Distensibility testing IVUS image measurements}

An IVUS catheter specified for the corresponding inner lumen diameter was positioned at center-length within each vessel. Philips (Andover, MA, USA) IVUS catheters (Eagle Eye Platinum ST or Visions PV8.2) were crosssectionally centered with rail-assistance via an .035 "

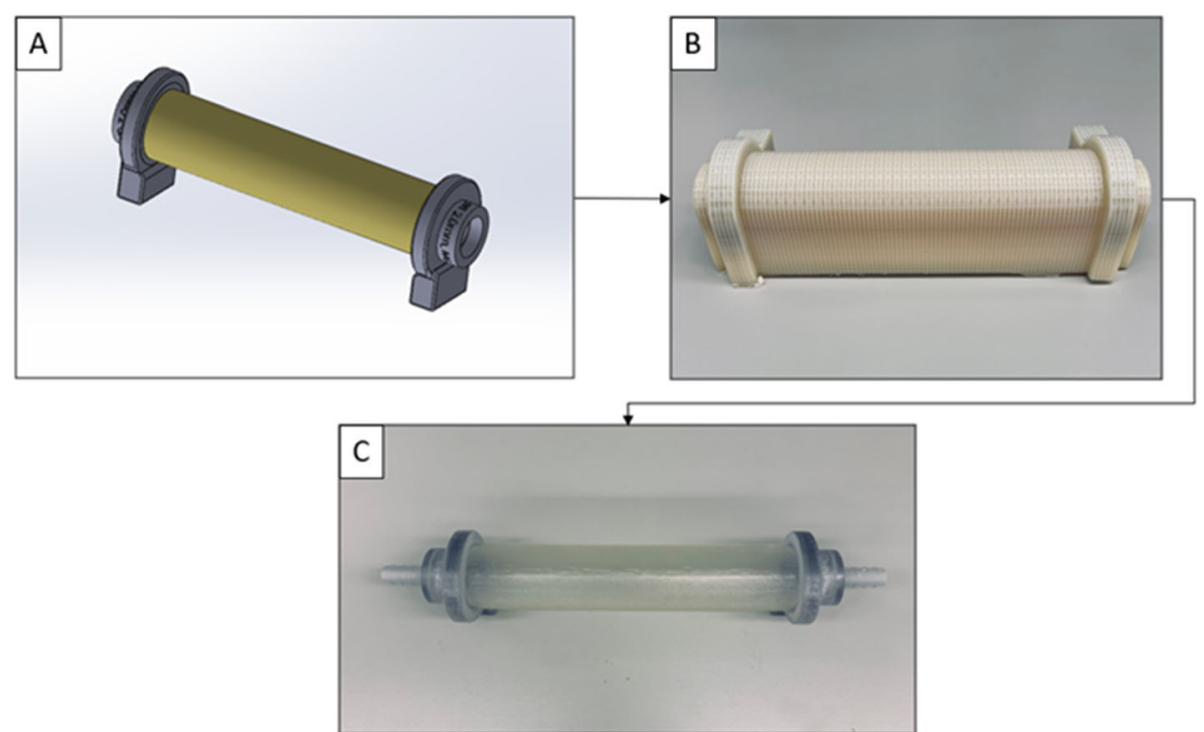

Fig. 2 Vessel Model Creation Process. A Vessel with inlet and outlet supports designed and assembled in Solidworks, ready to print; B Model successfully printed, still in support, ready for post-processing; $\mathbf{C}$ Model ready for testing with inlet and outlet connectors attached 


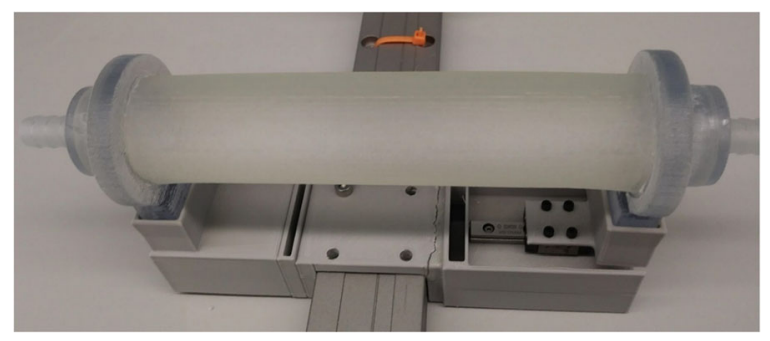

Fig. 3 Test vessel fixture allowing axial movement: left side of vessel is fixed, right side of vessel is attached to a linear bearing

\section{Pressure wire measurements}

Pressure was captured continuously from the Volcano system at $60 \mathrm{~Hz}$. The minimum, maximum, and MAP were obtained from the captured pressure waveform (Fig. 6).

\section{Target values \& distensibility determination}

Distensibility was calculated per equations below. Units are expressed as \% $\Delta$ Area / 100mmHg:

$$
\text { Distensibility }\left[\frac{\% \Delta \text { Area }}{100 \mathrm{mmHg}}\right]=\frac{\frac{\text { MaximumLumenArea }\left[\mathrm{mm}^{2}\right]-\text { MinimumLumenArea }\left[\mathrm{mm}^{2}\right]}{\text { MinimumLumenArea }\left[\mathrm{mm}^{2}\right]}}{\text { PulsePressure }[\mathrm{mmHg}] \times 100}
$$

$$
\text { PulsePressure }[\mathrm{mmHg}]=\text { Systolic(Maximum)Pressure }[\mathrm{mmHg}]
$$$$
\text { - Diastolic(Minimum)Pressure[mmHg] }
$$
were held for 2 min before measurements began, with stability confirmed by unchanged MAP value between 0 and $2 \mathrm{~min}$. A $15 \mathrm{~s}$ IVUS reading was recorded. Pressure (MAP, Systolic, Diastolic, and Pulse Pressure) was also simultaneously recorded during this time.

The IVUS hardware captures videos of the pulsating vessels at 12 to 30 frames per second. Using the longitudinal view, the user visually identified locations of minimum diameter, representing diastole and maximum diameter representing systole for three separate cardiac cycles (Fig. 5). Cross-sectional area $\left(\mathrm{mm}^{2}\right)$ was then measured from each image using the IVUS console software.

\section{Testing conditions}

All vessel test conditions achieved target MAP and pulse pressure. Table 3, below, identifies mean recorded MAP and pulse pressure for each tested vessel type.

All vessel cross-sectional area measurements were successfully taken using the IVUS software (Fig. 7). The area measurements were then used for distensibility calculations.

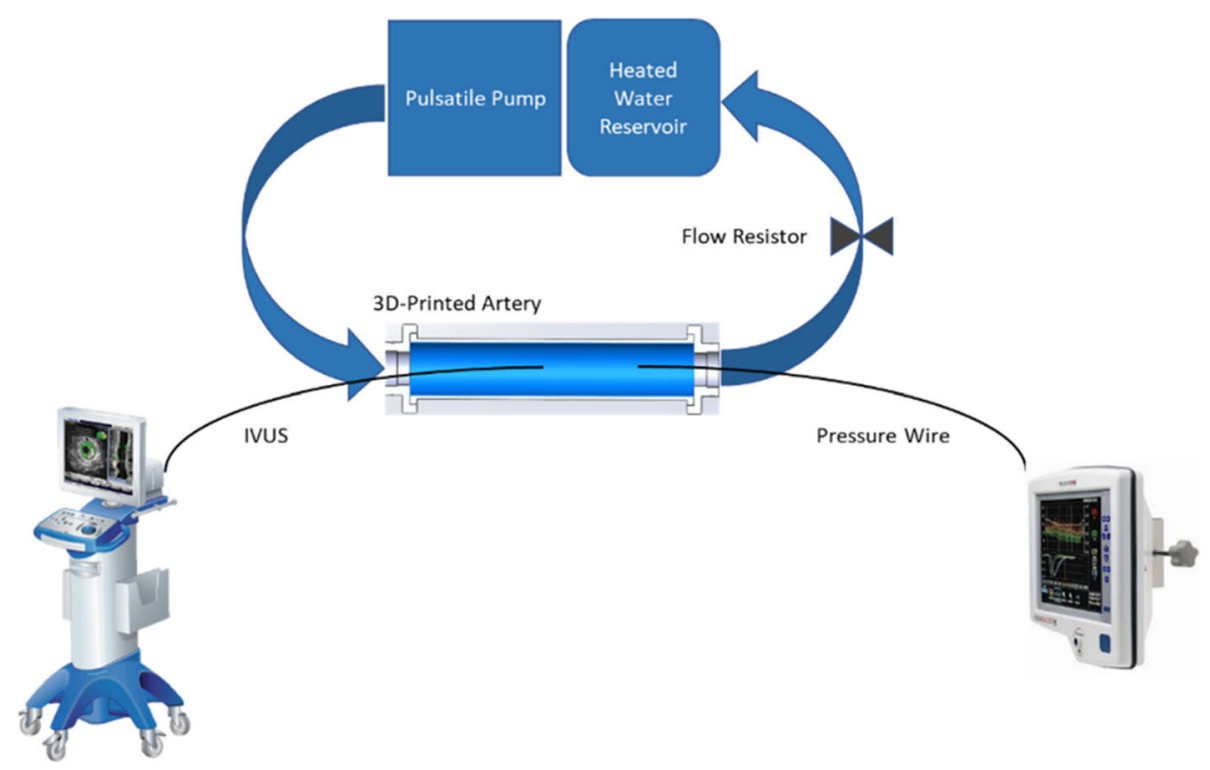

Fig. 4 Flow System Setup 


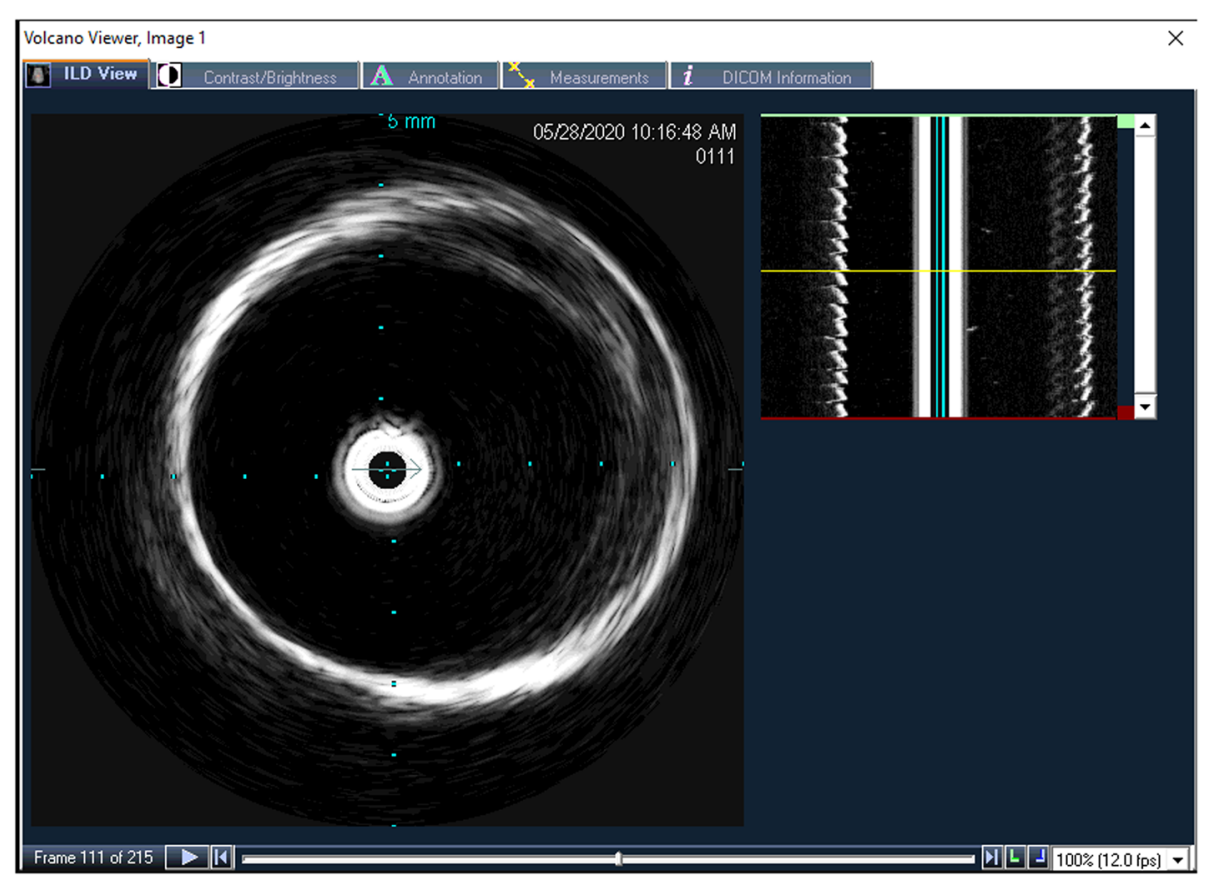

Fig. 5 IVUS In-line Digital Display layout shows the transverse view of an artery on the left and the corresponding time-lapse longitudinal view on the right. The yellow bar in the longitudinal view is a cursor control defining the time of the transverse view, with time increasing as the yellow bar moves down. The arrow in the center of the transverse view is a cursor control for defining the angular orientation of the longitudinal view. The diastole and systole positions are identified by the widest and narrowest points within the longitudinal view

\section{Distensibility}

Nine samples of each vessel type were tested. There were three replicates of each of the three materials: 'compliant', 'semi compliant', and 'rigid'. Compliant exhibited the highest distensibility, whereas rigid corresponded with the lowest distensibility. The measured distensibility values had a decreasing trend as materials moved from compliant to rigid (Fig. 8).

\section{Aorta cross-sectional distensibility}

Figure 8 (top graph) is an individual value plot displaying calculated distensibility results per material type where target literature range is represented by the area between the 2 dotted red lines. 'Compliant' (3 of 3 samples) and 'slightly compliant' ( 2 of 3 samples) fell within the target range for aorta cross sectional distensibility.

\section{Carotid cross-sectional distensibility}

An individual value plot displaying calculated distensibility results per material type where target literature range is represented by the area between the two dotted red lines (Fig. 8, middle graph). 'Compliant' (2 of 3 samples) and 'slightly compliant' (1 of 3 samples) vessels fell within the target range for carotid cross sectional distensibility.

\section{Coronary cross-sectional distensibility}

Figure 8 (bottom graph) consists of an individual value plot displaying calculated distensibility results per material type where target literature range is represented by the area between the 2 dotted red lines. 'Slightly compliant' (1 of 3 samples) and 'rigid' (3 of 3 samples) vessels fell within the target range for coronary cross sectional distensibility.

Based on the results of our study, recommended material assignment and wall thickness have been identified for the vessel types analyzed (Table 4).

\section{Discussion}

Simulation of endovascular intervention demands clinical relevancy, and material jetting 3D printing presents a solution for mimicking vascular distensibility. For the first time, 3D printed vascular models on a J750 were analyzed using intravascular ultrasound and successfully demonstrated the potential to accurately represent the distensibility of human arteries.

Target distensibility values were referenced from clinical studies varying in patient disease-state, sex, and age range. The use of IVUS allows for the capture of dynamic response, which is the only way to capture the non-linear response of the material in pulsatile physiological conditions. While static measurements may be 


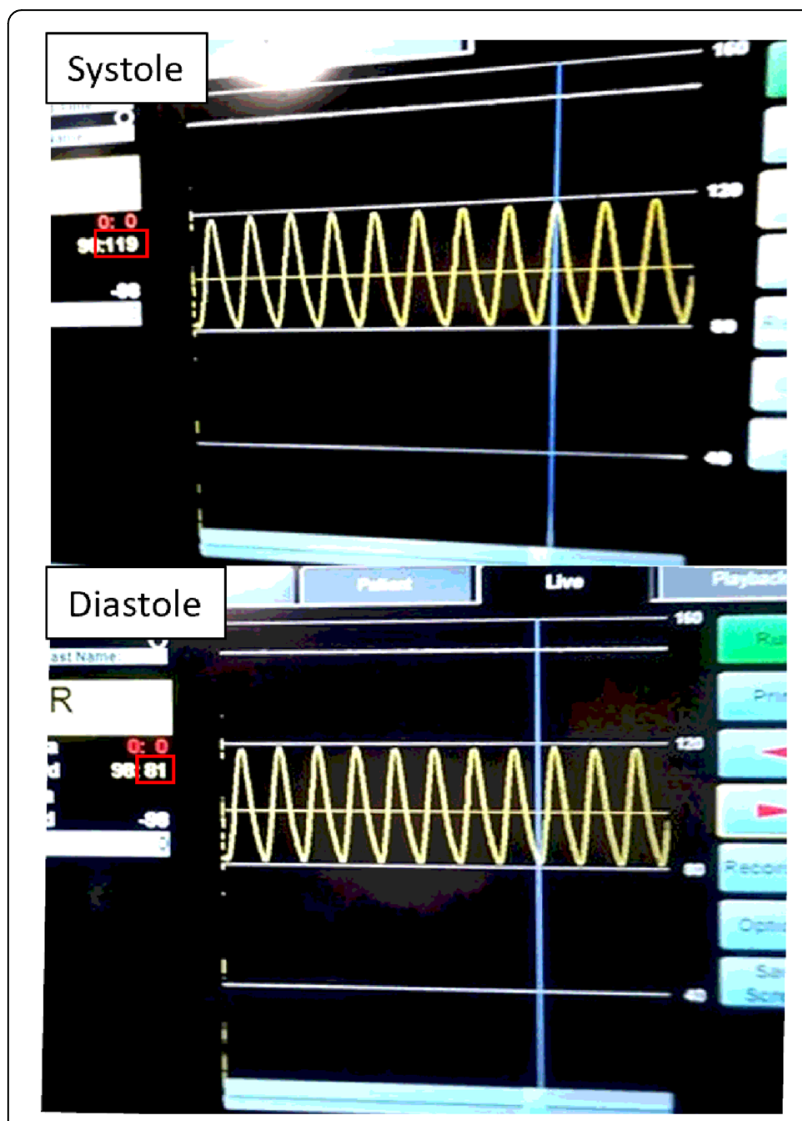

Fig. 6 Pressure wire display layout shows the pressure value over time. The vertical line is a cursor finding the time of the pressure data point

more stable, it introduces error related to how the material responds dynamically due to its elastic properties. A vessel at static pressure may not have the same crosssectional area as a vessel in physiological pulsatile flow at that same pressure. The clinical data was captured dynamically, therefore the test conditions were matched to make the most direct comparison.

By integrating controlled mechanical properties to vascular anatomical models, the utility of these models can be expanded to perform meaningful endovascular device testing in known physiological conditions. Recognizing that both material and geometrical factors contribute to the overall model properties, there is significant

Table 2 Clinical target distensibility per artery type

\begin{tabular}{|c|c|c|}
\hline $\begin{array}{l}\text { Artery } \\
\text { Type }\end{array}$ & $\begin{array}{l}\text { Target Distensibility [ \% } \\
\Delta \text { Area / 100mmHg] }\end{array}$ & Population \\
\hline Aorta & $10.3-44.0[18]$ & $\begin{array}{l}57 \pm 11 \text { year (standard } \\
\text { deviation), normal \& diseased }\end{array}$ \\
\hline Carotid & $5.1-10.1[27]$ & $\begin{array}{l}21-75 \text { year, normal \& } \\
\text { hypertensive }\end{array}$ \\
\hline Coronary & $0.5-6.0[26]$ & 50-85 year, healthy \& diseased \\
\hline
\end{tabular}

Table 3 Hemodynamics across all material types during testing

\begin{tabular}{lcc}
\hline Artery Type & Mean MAP [mmHg] & Mean Pulse Pressure [mmHg] \\
\hline Aorta $(n=9)$ & $99.6 \pm 0.7$ & $40.1 \pm 0.7$ \\
Carotid $(n=9)$ & $99.2 \pm 0.9$ & $40.2 \pm 1.5$ \\
Coronary $(n=9)$ & $98.6 \pm 1.9$ & $40.4 \pm 1.8$
\end{tabular}

Results reported as Mean \pm Standard Deviation

opportunity to improve the clinical accuracy of these models. In the endovascular space, devices traverse through the blood vessels to reach target locations and perform specific functions. The distensibility of a blood vessel is a key factor in endovascular device performance metrics such as the ability to track a device to a desired location, how a stent maintains its position within an artery when deployed, or how a device fills an aneurysm.

This feasibility study is limited by a small sample size, simplified anatomical test geometries, and limited blood vessel locations. There are other features important to vascular models that were not explored. The focus of this study is distensibility, but other properties such as lubricity, clarity, and toughness are also important features for vascular models.

Further characterization testing could increase the understanding of the relationships of wall thickness and vessel diameter to distensibility, which could inform the creation of a look-up chart to select parameters to reach a target distensibility. Further research into material modulation, including voxel-based or multi-layer designs, will contribute to the ability to design arteries representing more specific populations i.e., healthy vs. diseased, old vs. young.

The results of this study indicate the $\mathrm{J} 750$ provides an appropriate range of arterial distensibility to fit research and clinical needs in 3D printed vascular models.

\section{Conclusions}

When simulating arteries for treatment planning, education, and product testing, the distensibility of arteries is important in understanding how the artery will move as internal and external forces are applied. Arteries are dynamic structures that expand as a result of internal blood pressures. This study suggests the J750 and its associated materials can create arterial models that are biomechanically at, or close to, target physiological values representing a generalized population of healthy and diseased vessels. The realism of models produced by the 7750 can provide tremendous value by enabling use of models with accurate distensibility in simulations. In addition, this study demonstrates that it is both feasible and appropriate to utilize IVUS as an appropriate method to characterize distensibility in vascular models. 


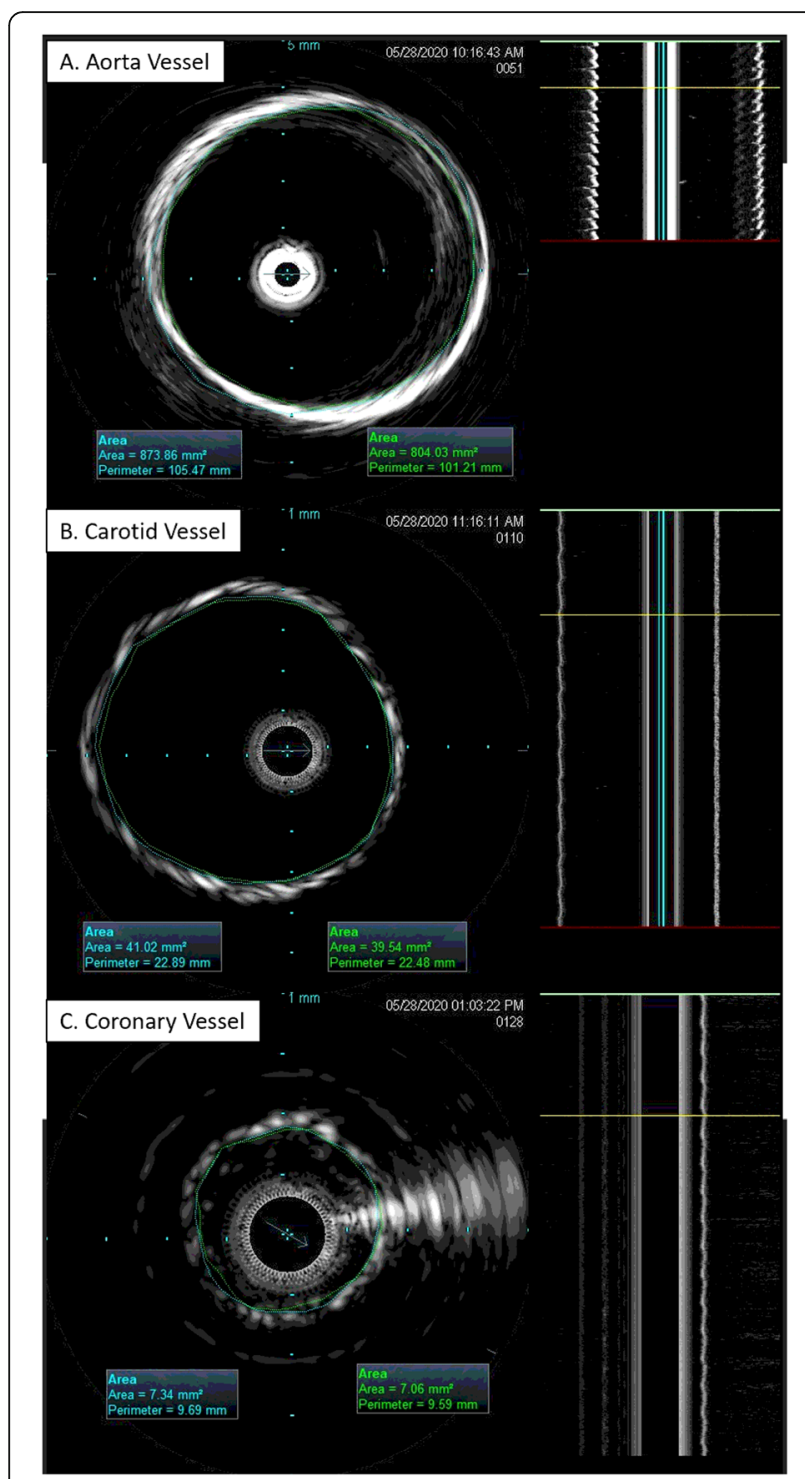

Fig. 7 Sample IVUS cross-sectional area measurements of systolic (blue) and diastolic (green) conditions. Frames $\mathbf{A}-\mathbf{C}$ are in the diastolic position of each vessel. Sample vessels $\mathbf{A}-\mathbf{C}$ were printed in the 'compliant' material 


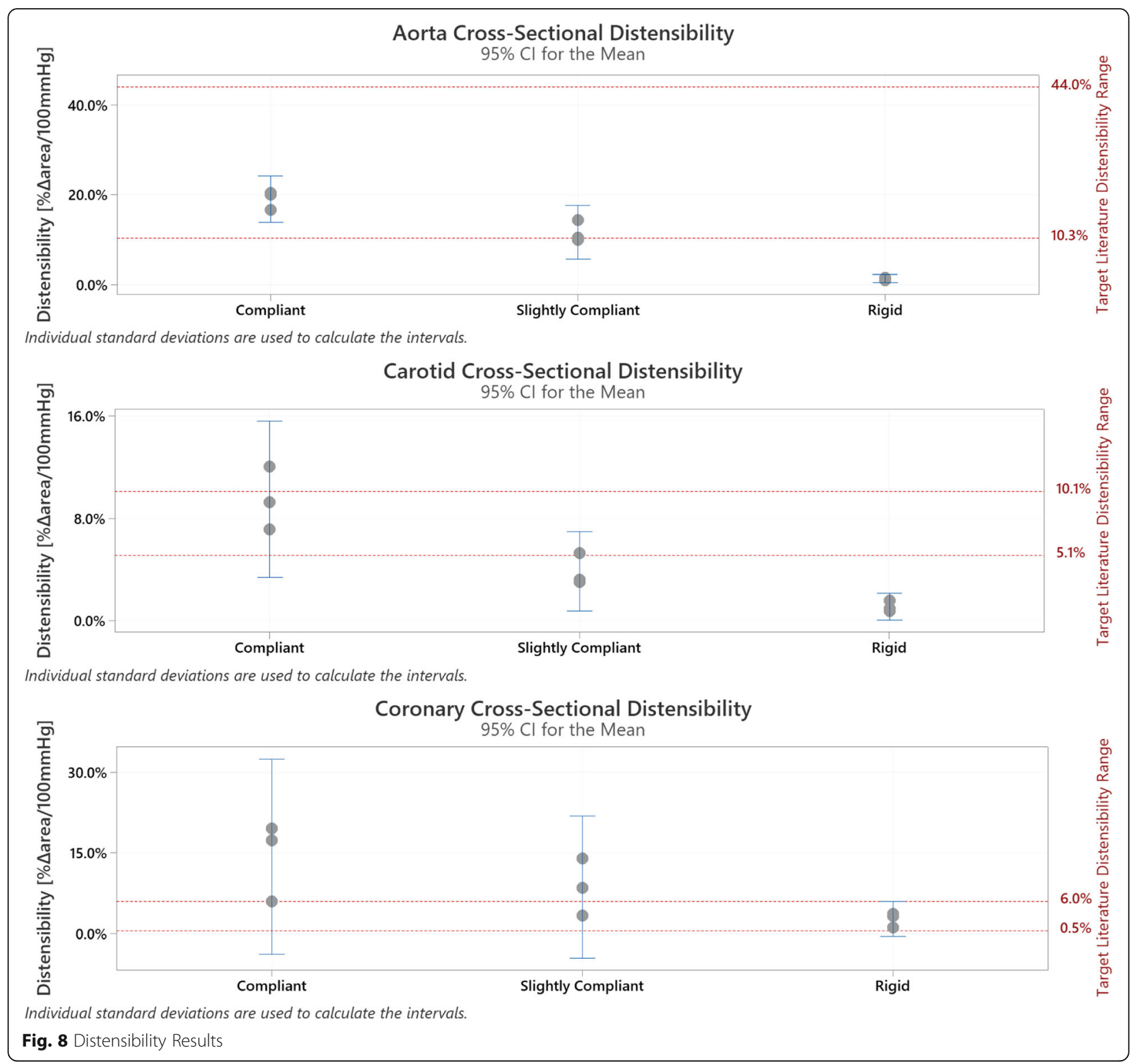

Table 4 Recommended design parameters for distensible arteries

\begin{tabular}{lcll}
\hline Vessel Type & Inner Diameter [mm] & Wall Thickness [mm] & Material \\
\hline Aorta & 30 & 3 & Compliant, Slightly Compliant \\
Carotid & 9 & 1.5 & Compliant, Slightly Compliant \\
Coronary & 3 & 1 & Slightly Compliant, Rigid \\
\hline
\end{tabular}




\section{Abbreviations}

3DP: 3D Printing; GUI: Graphic User Interface; IVUS: Intravascular Ultrasound; MAP: Mean Arterial Pressure; STL: STereoLithography

\section{Acknowledgements}

Acknowledgement to Joe Affronte for providing guidance and instruction on using the IVUS and pressure system.

\section{Authors' contributions}

Test samples were prepared by AS and CS. AS and CS executed testing performed data collection. IVUS measurements were performed by CS. Results were analyzed by $C S, A S, R D$, and MS. AA, JS, KM and MW contributed to writing the manuscript. All authors read and approved the final manuscript.

\section{Funding}

This study was partially supported by the Jacobs Institute and the New York Empire State Development Grant.

\section{Availability of data and materials}

The data that support the findings of this study are available from The Jacobs Institute, but restrictions apply to the availability of these data, which were used under license for the current study, and so are not publicly available. Data are however available from the authors upon reasonable request and with permission of The Jacobs Institute.

\section{Declarations}

\section{Ethics approval and consent to participate}

Not applicable.

\section{Consent for publication}

Not applicable.

\section{Competing interests}

The authors declare that they have no competing interests.

\section{Author details}

${ }^{1}$ The Jacobs Institute, Buffalo, New York, USA. ${ }^{2}$ Department of Neurosurgery, University at Buffalo, State University of New York, 100 High Street, Suite B4, Buffalo, NY 14203, USA. ${ }^{3}$ Canon Stroke and Vascular Research Center, University at Buffalo, State University of New York, Buffalo, New York, USA

Received: 14 September 2020 Accepted: 3 July 2021

Published online: 03 September 2021

\section{References}

1. Benjamin Emelia J, Muntner P, Alonso A, et al. Heart disease and stroke statistics - 2019 update: a report from the American heart association. Circulation. 2019;139(10):e56-28. https://doi.org/10.1161/CIR. 0000000000000659.

2. Lee S, Lee S, Kim S, et al. Fabrication and characterization of a magnetic drilling actuator for navigation in a three-dimensional phantom vascular network. Sci Rep. 2018;8 https://doi.org/10.1038/s41598-018-22110-5.

3. Costa PF, Albers HJ, Linssen JEA, et al. Mimicking arterial thrombosis in a 3D-printed microfluidic in vitro vascular model based on computed tomography angiography data. Lab on a chip. 2017;17(16):2785-92. https:// doi.org/10.1039/c7lc00202e.

4. Meess K. Development of Additive Manufactured Abdominal Aortic Aneurysm Phantoms For Minimally Invasive Endovascular Image Guided Procedures. Order No. 13885963 ed. State University of New York at Buffalo; 2019. ProQuest, https://www.proquest.com/docview/2305528338?a ccountid=14169.

5. Kono K, Shintani A, Okada H, Terada T. Preoperative simulations of endovascular treatment for a cerebral aneurysm using a patient-specific vascular silicone model. Neurol Med Chir. 2013;53(5):347-51. https://doi. org/10.2176/nmc.53.347.

6. McClure RS, Fedak PWM, Commentary. Using ex vivo modeling to validate technical innovations in cardiac surgery. J Thoracic Cardiovasc Surg. 2019; 158(2):404-5. https://doi.org/10.1016/j.jtcvs.2019.02.010.
7. Shepard LM, Sommer KN, Angel E, et al. Initial evaluation of threedimensionally printed patient-specific coronary phantoms for CT-FFR software validation. J Med Imaging. 2019;6(2):021603. https://doi.org/10.111 7/1.JMI.6.2.021603.

8. Chepelev L, Wake N, Ryan J, et al. Radiological Society of North America (RSNA) 3D printing Special Interest Group (SIG): quidelines for medical 3D printing and appropriateness for clinical scenarios. 3D Print Med. 2018;4(1): 11. https://doi.org/10.1186/s41205-018-0030-y.

9. Tabaczynski J, Stoll T, Shepard L, et al. Use of patient specific 3D printed (3DP) neurovascular phantoms for mechanical assessment of devices used in image guided minimally invasive procedures. Proc SPIE Int Soc Opt Eng. 2018;10579:105790K. https://doi.org/10.1117/12.2293370.

10. Ionita CN, Mokin M, Varble N, et al. Challenges and limitations of patientspecific vascular phantom fabrication using 3D Polyjet printing. Proc SPIE Int Soc Opt Eng. 2014;13:90380M. https://doi.org/10.1117/12.2042266.

11. Tabaczynski J. Mechanical Assessment of 3D Printed Patient Specific Phantoms for Simulation of Minimally Invasive Image Guided Procedures. Order No. 10823110 ed. State University of New York at Buffalo; 2018. ProQuest, https://www.proquest.com/docview/2057213064?accountid=141 69.

12. Mogali SR, Yeong WY, Tan HKJ, et al. Evaluation by medical students of the educational value of multi-material and multi-colored three-dimensional printed models of the upper limb for anatomical education. Anat Sci Educ. 2018;11(1):54-64. https://doi.org/10.1002/ase.1703.

13. Nagesh SVS, Russ M, Ionita CN, Bednarek D, Rudin S. Use of patient specific 3D printed neurovascular phantoms to evaluate the clinical utility of a high resolution x-ray imager. Proc SPIE Int Soc Opt Eng. 2017;10137. https://doi. org/10.1117/12.2254390.

14. Shepard LM, Sommer KN, Angel E, et al. CT investigation of patient-specific phantoms with coronary artery disease. Proc SPIE Int Soc Opt Eng. 2018; 10573:105731V. https://doi.org/10.1117/12.2292918.

15. Mitsouras D, Lee TC, Liacouras $P$, et al. Three-dimensional printing of MRIvisible phantoms and MR image-guided therapy simulation. Magnetic resonance in medicine. 2017;77(2):613-22.

16. Poulin E, Gardi L, Fenster A, Pouliot J, Beaulieu L. Towards real-time 3D ultrasound planning and personalized 3D printing for breast HDR brachytherapy treatment. Radiother Oncol. 2015;114(3):335-8. https://doi. org/10.1016/j.radonc.2015.02.007.

17. Laurent S, Caviezel B, Beck L, et al. Carotid artery distensibility and distending pressure in hypertensive humans. Hypertension. 1994;23(6 Pt 2): 878-83. https://doi.org/10.1161/01.hyp.23.6.878.

18. Tobey D, Reynolds T, Kopchok G, Donayre C, Khoynezhad A, White R. In Vivo Assessment of Ascending \& Arch Aortic Compliance. Ann Vasc Surg. 2018;08/01:270. https://doi.org/10.1016/j.avsg.2018.05.003.

19. Alfonso F, Macaya C, Goicolea J, et al. Determinants of coronary compliance in patients with coronary artery disease: an intravascular ultrasound study. J Am Coll Cardiol. 1994;23(4):879-84. https://doi.org/10.1016/0735-1097(94 )90632-7.

20. Whincup PH, Gilg JA, Donald AE, et al. Arterial distensibility in adolescents the influence of adiposity, the metabolic syndrome, and classic risk factors. Circulation. 2005;112(12):1789-97. https://doi.org/10.1161/CIRCULATIONA HA.104.532663.

21. Robinson M, Scheuermann-Freestone M, Leeson $\mathrm{P}$, et al. Uncomplicated obesity is associated with abnormal aortic function assessed by cardiovascular magnetic resonance. J Cardiovasc Magnet Reson. 2008;02/13: 10. https://doi.org/10.1186/1532-429X-10-10.

22. Sommer $K$, Izzo RL, Shepard $L$, et al. Design optimization for accurate flow simulations in $3 \mathrm{~d}$ printed vascular phantoms derived from computed tomography angiography. Proc SPIE Int Soc Opt Eng. 2017;10138. https:// doi.org/10.1117/12.2253711.

23. Russ $M$, apos, Hara $R$, et al. Treatment planning for image-guided neuro-vascular interventions using patient-specific 3D printed phantoms. Proc SPIE Int Soc Opt Eng. 2015;9417:941726. https://doi.org/10.111 7/12.2081997.

24. Vriz $O$, Aboyans $V$, Minisini $R$, et al. Reference values of one-point carotid stiffness parameters determined by carotid echo-tracking and brachial pulse pressure in a large population of healthy subjects. Hypertens Res. 2017; 40(7):685-95. https://doi.org/10.1038/hr.2017.24.

25. Shaw JA, Kingwell BA, Walton AS, et al. Determinants of coronary artery compliance in subjects with and without angiographic coronary artery disease. J Am Coll Cardiol. 2002;39(10):1637. https://doi.org/10.1016/S0735-1097(02)01842-9. 
26. Meess KM, Izzo RL, Dryjski ML, et al. 3D printed abdominal aortic aneurysm phantom for image guided surgical planning with a patient specific fenestrated endovascular graft system. Proc SPIE Int Soc Opt Eng. 2017; 10138:101380P-101380P - 14. https://doi.org/10.1117/12.2253902.

27. Allman AB, Shepard LM, Podgorsak AR, Rava RA, Ionita CN. Controlled compliancy of 3D printed vascular patient specific phantoms. Proc SPIE Int Soc Opt Eng. 2019;10954:109540C. https://doi.org/10.1117/12.2512528.

28. Williams MJ, Stewart RA, Low CJ, Wilkins GT. Assessment of the mechanical properties of coronary arteries using intravascular ultrasound: an in vivo study. Int J Card Imaging. 1999;15(4):287-94. https://doi.org/10.1023/a:10062 79228534

29. Peelukhana SV, Wang Y, Berwick Z, et al. Role of pulse pressure and geometry of primary entry tear in acute type $B$ dissection propagation. Ann Biomed Eng. 2017;45(3):592-603. https://doi.org/10.1007/s10439-016-1705-4.

30. Ostchega $Y$. Resting pulse rate reference data for children, adolescents, and adults: United States, 1999-2008 / by Yechiam Ostchega [and four others]. National health statistics reports; number 41. U.S. Department of Health and Human Services, Centers for Disease Control and Prevention, National Center for Health Statistics; 2011.

\section{Publisher's Note}

Springer Nature remains neutral with regard to jurisdictional claims in published maps and institutional affiliations.

Ready to submit your research? Choose BMC and benefit from:

- fast, convenient online submission

- thorough peer review by experienced researchers in your field

- rapid publication on acceptance

- support for research data, including large and complex data types

- gold Open Access which fosters wider collaboration and increased citations

- maximum visibility for your research: over $100 \mathrm{M}$ website views per year

At BMC, research is always in progress.

Learn more biomedcentral.com/submissions 